\title{
Having experiences, doing experiments
}

\begin{abstract}
Joan Mascaró, in the book The Creation of Faith, ${ }^{1}$ proposed that consciousness, thought, will, spirituality is empirical phenomena of experience that should not be a problem to science. It is true that for some strange reason scientific positivism has generally been conceived as totally antagonistic to the study of spirituality and to the sensitivities of the human soul in general. But, are not these psychological phenomena like any other? Why must not science study them? Did not about objective facts of experience? He wonders.
\end{abstract}

Volume 4 Issue 4 - 2015

\author{
Joan Torello \\ IES Santa Margalida, Spain
}

Correspondence: Joan Torello, Conselleria d'Educacio de les
Illes Balears, Rota des Pinar 12, Maria, Illes Balears, Spain, Tel 971525748, Email joantorellomas@gmail.com

Received: November 18, 2015 | Published: December 07, 2015

\section{Introduction}

Spirituality is a fact manifested in subjective experiences (all psychological manifestations are subjective) that can be subject of scientific study, like any human behavior. These are personal, measurable, real experiences, beyond the dogmas of religion. It will seem paradoxical, but science and spirituality, in the background, they share the same objective: to know the 'truth', understand the working of reality. Simply. The raw material for scientific research are empirical experiences, which are events of personal experience as any other, as are, of course, spiritual experiences. Scientists simply create specific, controlled conditions of laboratory, in order to experience, in the broadest sense of the word, events that do not occur regularly in everyday life. What is at issue in science is to create the conditions to experiment new phenomena for people who are researching. To experiment is to have new experiences, to compose certain conditions to have a personal experience of perception of reality, as we have in any everyday psychological experience at any time, or in a spiritual or emotional or aesthetic experience.

Science and religion are (or should be) something very similar, if not the same thing. Joan Mascaró said it in a straightforward manner: 'The spiritual experience, as scientific experiments, is based on the observation of facts.' 'There is inner observation and experiment and outer observation and experiment. From the first comes poetry, spiritual vision and all human values; from the second, science and technology.' 'If science is one, religion must be one. Science is based on experiment; religion should be based on experience.' 'Pure consciousness should observe the experience.'

Spirituality and science, in the background, share object and method: observation of the facts of empirical experience. The difference between spirituality and science is 'just' of perspective, is that spirituality has an overall view of nature as a whole (which corresponds to the idea of God), while science has a partial view of the constituent parts of nature. So spirituality has to appeal to the contemplative observation and imagination to encompass the whole, unable to reason or understand the discrete elements; while science uses analytical thought and observation of isolated elements of a complex whole that is very difficult to encompass item by item. Spirituality needs of imagination to maintain overall articulation, needs faith, needs to trust that things are or may be in a certain way, because cannot observe or certify element by element, unlike science. The problem with spirituality is that it fails to go deeply into any concrete subject in order to keep the vision of the whole, does not explain any particular aspect of nature, has to conform to the faith and 'contemplation' of the whole; while the problem of science is that it almost never comes to appreciate the whole of reality, the real functioning of hidden reality because thoroughly analyzes elements but is not able to articulate one with each other. So truth, the meaningful of truth, what is relevant to people, is beyond the scope of science normally.

Mascaró wrote: 'Life avoids the microscope and the telescope.' 'Appearance is the visible world, the reality is the unseen world.' 'When you see the many forget the All. God is the All.' 'The world of the poet and of the artist is more real than the object of physical science.' 'Analyze the whole into its constituent parts is useful; but what do you say about contemplation of all? Because the whole is much more than its parts, the whole cannot be understood by analysis but by synthesis, synthesis of contemplation. Contemplation is beyond thought.'

The important thing is to know the truth, understand the working of reality either by way of science or by way of spirituality, it is indifferent. The debate one way against the other is completely sterile. The only thing that can bring us freedom and happiness is empirical knowledge of the world, just with tools of observation, thought and imagination, regardless of the framework within they are used. What is needed is to always go beyond, discover, and keep learning... Anything else is deadlock, empty words, dogma. Knowledge, which is to capture the order of nature and its becoming, is what makes us free. Capturing intelligence or 'logos' that exist in nature is like capturing God. Freedom and happiness of people lies precisely in that, in understanding the world.

'The thought must have freedom to think. But there is only freedom in truth. We are not free to think that $2+2=5$ ! If we do we are not free, we are in the bondage of error.' 'You are free to play wrong notes on the piano, but that will not produce music. The freedom to make music comes from playing the correct notes.' 'We are not free to see the sun if we close our eyes. As the harp string is subject to fixed rules just get the freedom of music.' 'The task of man on earth is to learn to read and write, to read the life and to write the life.' 'There is only one truth in the universe. Science is one and religion is one, but there are many false religions.' 'The world needs a new religion, a new philosophy of life free from dogmatism of science and technology and free from dogmatism of organized religion.'

The true path is neither science nor religion per se, but a harmony between observation and imagination, reciprocity between the two. It is the way of observation directed by imagination, while imagination 
controlled by observation. It is the way of empirical reality, the truth that feeds on reality. The way of discovery is imagination that raises new possibilities beyond thought, but at the time verifies its reality by thought.

'Just reason and spiritual imagination both together can do man self-sufficient: reason and God who has given us the reason.' 'The ideas come from the imagination.' 'Imagination is an intensity of consciousness.' 'What matters is an inner experience verified by the wisdom of reason.' 'It's the experience that matters, not the concept.' 'Intuition is an experience, not a thought.'

Words themselves do not lead reason. Reason lies in truth and truth in reality. What is at issue, then, is to do science, but empirical science of things that really matter.

\section{Acknowledgments}

None.

\section{Conflicts of interest}

Author declares there are no conflicts of interest.

\section{Funding}

None.

\section{References}

1. Mascaró J. The Creation of Faith, Moll, Palma de Mallorca. 1993. 